\title{
Control Design for PMM-based Generator fed by Active Front-End Rectifier in More-Electric Aircraft
}

\author{
Mingming Yin, Serhiy Bozhko, and Seang Shen Yeoh \\ University of Nottingham
}

\begin{abstract}
The future aircraft electrical power system is expected to be more efficient, safer, simpler in servicing and easier in maintenance. As a result, many existing hydraulic and pneumatic power driven systems are being replaced by their electrical counterparts. This trend is known as a move towards the More-Electric Aircraft (MEA). As a result, a large number of new electrical loads have been introduced in order to power many primary functions including actuation, de-icing, cabin airconditioning, and engine start. Therefore electric power generation systems have a key role in supporting this technological trend. Advances in modern power electronics allow the concept of starter/generator $(\mathrm{S} / \mathrm{G})$ which enables electrical engine start and power generation using the same electrical machine. This results in substantial improvements in power density and reduced overall weight. One of the potential S/G solutions is to employ a permanent magnet machine (PMM) controlled by active front-end rectifier (AFE). Operation of the PMM as a generator at wide range of speed that is dictated by the engine and electrical loads connected to the aircraft bus require careful design of the controllers. Corresponding plant models are derived and verified with simulations using developed models in Matlab/Simulink. The relevant controllers are designed based on the derived plants and operating points. The controllers are tested with Simulink models and experimentally using a scaled prototype of the investigated generator system.
\end{abstract}

Key words: permanent magnet generator, flux weakening, control design, DC link voltage, more electric aircraft

\section{Introduction}

The present aircraft systems technologies need to have significant changes for the sake of tendency to be more efficient and environmentally-friendly. The More-Electric Aircraft (MEA) is one of the main trends in modern aircraft engineering aiming to replace the conventional aircraft topology [1]. The subsystems that used mechanical, pneumatic, hydraulic power now are to be partially or completely substituted by electrical systems which result in significant increased on-board electric power demand. Hence the role of electrical power generation system is of great importance.

The current electrical power generation system on-board most aircrafts normally employs three-stage wound field synchronous generators. This generator has been extensively adopted in fixed wing and rotor craft applications and has proved to be highly reliable and inherently safe. However, there is a limit of increasing the power density due to electronic components located on the rotor. Additional exciter windings are required for electrical start operation which increases the overall machine weight [3]. Advances in modern power electronic converters make it possible to re-configure the power generation system while considering other machine types such as the

Page 1 of 6 permanent magnet machine (PMM), induction machine (IM), and switched reluctance machine (SR) [2] [5].

In addition, electric engine start function can be incorporated using the machine for starter/generator $(\mathrm{S} / \mathrm{G})$ scheme. It is one of the most significant change brought by the MEA concept that offers advantages such as reduction of aircraft empty weight, less maintenance downtime, lower cost and improved reliability [4][6][7][8].

In terms of control strategies for aircraft $S / G$ system, there are several papers reporting on this [9][10][11][12]. Based on variable speed drive application, a control strategy of the doubly fed induction generator is achieved by inner flux control loop and stator-voltage outer loop in [9]. A control methodology which utilizes angle and speed estimation algorithm is presented [10]. The high frequency voltage signal and the subsequent demodulation of high frequency stator current make it possible to achieve sensor-less operation of fulltorque from zero speed to ignition speed. Detailed control design of the PMM-based S/G has been studied in [11] and [12]. These papers consider regulation of DC link current during generating mode to accommodate droop control for possible parallel operation of multisource aircraft power system. Detailed design and analysis of DC link voltage controller that is typically used for stand-alone power systems has yet to be investigated. In addition to that, the stability of FW controller during generator mode still needs to be analyzed to ensure stable operation throughout the generator speed operating range. This paper aims to fill in the gaps for both of these controllers by detailed plant derivation and control design analysis in generator mode. The paper shall cover the control design of the S/G system in generator mode only. More information on starter mode control can be found in [11] and [12].

The paper shall be structured as follows; the investigated generator system and the relevant model equations are introduced. The control structure is formed based on the requirements in generator mode. Next, the control plant for FW and DC link is derived from the equations to aid with the controller design process. They are verified at different operating points with equivalent non-linear models built in Matlab/Simulink environment. The controllers can be designed based on the derived plants and they are tested across the speed operating range in generator mode. Finally, the control design process is validated using a small prototype test rig followed by conclusions and possible future work.

\section{Power System}

One of the possible topology of MEA generator system that is investigated is shown in Figure 1. $\omega_{r}$ is the rotor speed, $C$ is the DC link capacitor, and $i_{a b c}$ is the three phase stator currents. $E_{d c}$ and $I_{d c}$ are the DC link voltage and current respectively. The power system consists of a PMM fed by an active front end rectifier (AFE) that is 
connected to the aircraft DC bus. In starter mode, the PMM is driven by the AFE to start the engine using electrical power from the ground power supply or auxiliary power unit (APU). In generating mode, the engine drives the PMM and the generated power is sent to the DC bus to supply onboard loads. They are generally represented as resistive and constant power type loads. The relevant equations (1)-(4) needed to represent the PMM, AFE, and DC bus is introduced to establish the average model of the generator system for control design process.

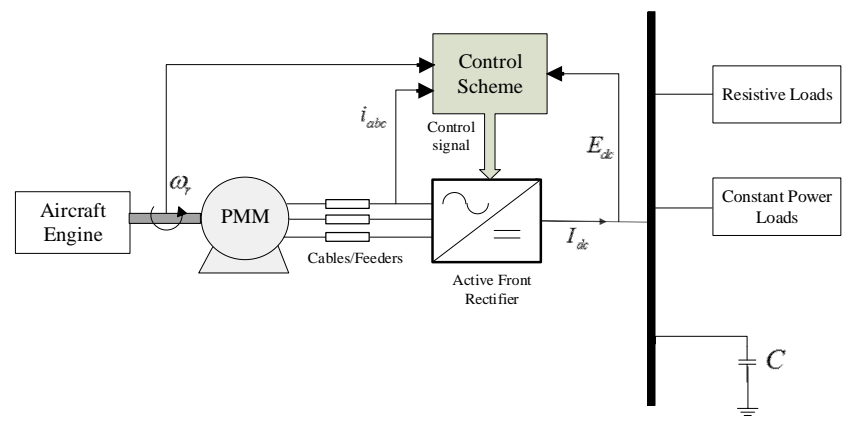

Figure 1. Typical generator system for MEA.

$v_{d}=R i_{d}+L_{d} \frac{d i_{d}}{d t}-\omega_{e} L_{q} i_{q}$

$v_{q}=R i_{q}+L_{q} \frac{d i_{q}}{d t}+\omega_{e} L_{d} i_{d}+\omega_{e} \psi_{m}$

$E_{d c} I_{d c}=\frac{3}{2}\left(v_{d} i_{d}+v_{q} i_{q}\right)$

$I_{d c}=C \frac{d E_{d c}}{d t}$

where $i_{d, q}, v_{d, q}$, and $L_{d, q}$ are the AC currents, voltages, and inductances respectively in $d q$ frame. $R$ is the stator resistance, $\omega_{e}$ is the electrical speed, and $\psi_{m}$ is the machine flux. The parameter values are shown in Table 1.

Table 1. Parameters of the system.

\begin{tabular}{|l|c|}
\hline \multicolumn{1}{|c|}{ Parameter } & Value \\
\hline Stator resistance, $R$ & $1.058 \mathrm{~m} \Omega$ \\
\hline$d$-axis inductance, $L_{d}$ & $99 \mu \mathrm{H}$ \\
\hline$q$-axis inductance, $L_{q}$ & $99 \mu \mathrm{H}$ \\
\hline Mutual flux, $\psi_{m}$ & $0.03644 \mathrm{Vs}$ \\
\hline Combined inertia, $J$ & $0.103 \mathrm{kgm}^{2}$ \\
\hline DC link capacitor, $C$ & $1.2 \mathrm{mF}$ \\
\hline Pole pairs, $p$ & 3 \\
\hline Maximum stator current, $i_{m}$ & $400 \mathrm{~A}$ \\
\hline Nominal DC link voltage, $E_{\text {dcrated }}$ & $270 \mathrm{~V}$ \\
\hline Rated power, $P_{\text {rated }}$ & $45 \mathrm{~kW}$ \\
\hline Generating speed range & {$[20 \mathrm{krpm}, 32 \mathrm{krpm}]$} \\
\hline
\end{tabular}

\section{Generator Mode Control Scheme}

Field oriented vector control is chosen as the control structure for the generator system as shown in Figure 2. Any symbols marked with $*$ are the reference value for the respective control variables. $i_{q l i m}$ is the limit value for $i_{q}{ }^{*}$ and $i_{m}$ is the maximum stator current. $|V|$ is the AC stator voltage magnitude and $v_{a b c}$ is the three phase voltages. $i_{a b c}$ is regulated in rotating reference frame $(d q)$ using the inner current controllers. The design of these controllers has been commonly adapted for drive systems. Following the generator mode of operation, $E_{d c}$ is controlled on the outer loop during generator mode. Flux weakening (FW) control is also employed to prevent over-modulation Page 2 of 6 of the AFE when the power system is operating in high speed regions. This is achieved by limiting $|V|$ using de-fluxing current dictated by $i_{d}{ }^{*}$. The controlled variables are regulated using well known PI based controllers. A dynamic limiter is present which determines the limit for $i_{q}{ }^{*}$ based on $i_{d}{ }^{*}$ and $i_{m}$ using the current limit equation [11]:

$i_{q l i m}=\sqrt{i_{m}^{2}-i_{d}^{2}}$

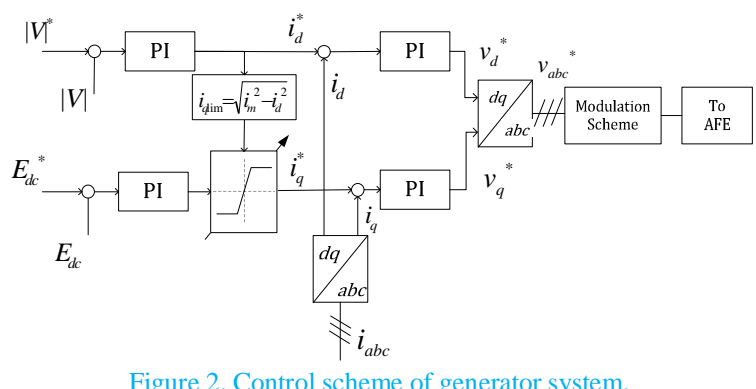

In this control structure, the speed of the aircraft turbine is assumed to be controlled externally. Another assumption is made whereby the generator system does not reach saturated $i_{q}{ }^{*}$ (load demand higher than load supply).

\section{Control Plant}

Some of the model equations contain non-linearity that can be linearized before being used for small signal analysis. The small signal models are obtained using Taylor's series around an operating point and are expressed as follows:

$\partial v_{d}=R \partial i_{d}+L_{d} s i_{d}-i_{q 0} L_{q} \partial \omega_{e}-\omega_{e 0} L_{q} \partial i_{q}$

$\partial v_{q}=R \partial i_{q}+L_{q} s \partial i_{q}+\omega_{e 0} L_{d} \partial i_{d}+\partial \omega_{e} L_{d} \partial i_{d 0}+\psi_{m} \partial \omega_{e}$

$\partial I_{d c}=\frac{3}{2 E_{d c 0}}\left(v_{d 0} \partial i_{d}+i_{d 0} \partial v_{d}+v_{q 0} \partial i_{q}+i_{q 0} \partial v_{q}\right) \partial i_{d}-\frac{3}{2 E_{d c 0}{ }^{2}}\left(v_{d 0} i_{d 0}+\right.$ $\left.v_{q 0} i_{q 0}\right) \partial E_{d c}$

The linearized voltage limit equation that is used to calculate $|V|$ is shown as [11]:

$\partial|V|=\frac{v_{d 0}}{|V|_{0}} \partial v_{d}+\frac{v_{q 0}}{|V|_{0}} \partial v_{q}$

where the variables with the subscript 0 are obtained around a specified operating point. The closed loop inner current transfer functions are shown as:

$T F_{i d, q}(s)=\frac{\partial i_{d, q}}{\partial i_{d, q}{ }^{*}}=\frac{\left(2 \xi \omega_{n} L_{d, q}-R\right) s+\omega_{n}^{2} L_{d, q}}{L_{d, q}\left(s^{2}+2 \xi \omega_{n} s+\omega_{n}^{2}\right)}$

The following sub-sections will detail the plant derivation for $E_{d c}$ and FW to aid with the controller design using the relevant linear equations. The respective controllers can then be designed depending on the worst case operating point. For this generator system, that operating point is found to be at $32 \mathrm{krpm}$ with full load connected to the DC bus $(45 \mathrm{~kW})$.

\section{Link Voltage Controller Design}

In this section, the plant is derived to relate output $\partial E_{d c}$ to input $\partial i_{q}{ }^{*}$ for the DC link controller design process. Using equation (4), (6), (7), and (8), the linear plant can be formulated as: 


$$
\partial E_{d c}=\frac{3 E_{d c 0}}{\left[3\left(v_{d 0} i_{d 0}+v_{q 0} i_{q 0}\right)-2 C S E_{d c 0}^{2}\right]}\left[\begin{array}{c}
\left(v_{q 0}+\left(R+L_{q} s\right) i_{q 0}-L_{q} \omega_{e 0} i_{d 0}\right) \partial i_{q} \\
+\left(v_{d 0}+\left(R+L_{d} s\right) i_{d 0}+L_{d} \omega_{e 0} i_{q 0}\right) \partial i_{d} \\
+\left(i_{q 0}\left(\psi_{m}+L_{d} i_{d 0}\right)-i_{d 0} i_{q 0} L_{q}\right) \partial \omega_{e}
\end{array}\right]
$$

Assuming that the change of speed is much slower than the electrical dynamics, then for the purpose of control design $\partial \omega_{e}$ can be assumed constant. $\partial i_{d}$ terms are considered as disturbances and are not considered as part of the plant. The $E_{d c}$ plant is derived with addition of (10) to form:

$\frac{\partial E_{d c}}{\partial i_{q}{ }^{*}}=T F_{i q}(s) \frac{3 E_{d c 0}\left[v_{q 0}+\left(R+L_{q} s\right) i_{q 0}-L_{q} \omega_{e 0} i_{d 0}\right]}{\left[3\left(v_{d 0} i_{d 0}+v_{q 0} i_{q 0}\right)-2 C s E_{d c 0}^{2}\right]}$

The plant is verified by comparing step response with a non-linear model of the generator system build in Simulink environment. A similar operating point at the highest speed range $(32 \mathrm{krpm})$ and full load is selected as an example for both models. Both of the step responses of $E_{d c}$ are shown in Figure 3. The two lines coincide with each other which signify that the derived transfer function can be used to represent the desired control plant. At the operating point, equation (12) is shown numerically as:

$\frac{\partial E_{d c}}{\partial i_{q}{ }^{*}}=\frac{-405\left(s-4.45 \times 10^{4}\right)(s+4449)}{\left(s^{2}+8884 s+3.948 \times 10^{7}\right)(s+627.9)}$

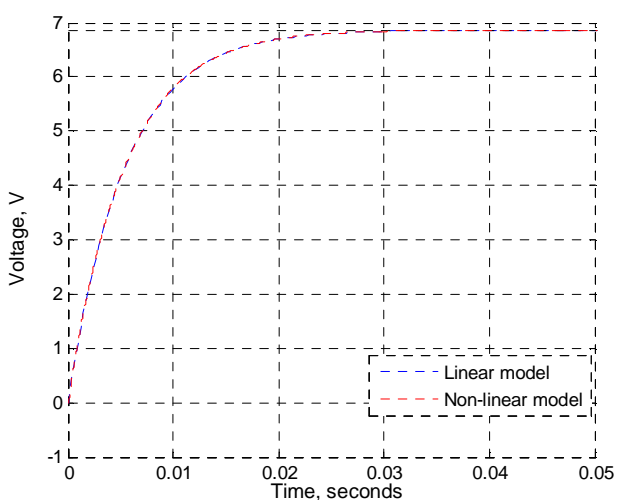

Figure 3. Open loop step responses to a step input of $i_{q}{ }^{*}=-1 \mathrm{~A}$ of the $E_{d c}$ plant (blue) and the non-linear Simulink model (red).

The transfer function is of third order and one of the zeroes $(4.45 \times$ $10^{4}$ ) is located on the right hand plane (RHP) that can be visualized on a root locus in Figure 4. This indicates a non-minimum phase system that may limit the stability of the controller.

In closed loop configuration together with the PI controller, the root loci shape is similar to the open loop plant. It can be seen that there is a limit range for the closed loop gain in Figure 5. The $E_{d c}$ proportional, $k_{p e}$, and integral term, $k_{i e}$, are increased relative to each other and it can be seen that the conjugate poles of the transfer function tend to move towards the RHP. The stability limit of the controller is when the poles are on the border between the left hand plane (LHP) and RHP. The system becomes unstable once the poles are on the RHP. At this operating point, the $E_{d c}$ controller stability limit is found to be about $k_{p e}=13$ and $k_{i e}=1300$. The closed loop step response of $E_{d c}$ can be seen in Figure 6 which confirms the controller stability range. $k_{p e}=$ 1 and $k_{i e}=100$ are selected for the $E_{d c}$ controller which provides satisfactory dynamic response and capability of operating up to the highest speed with full load operating point.

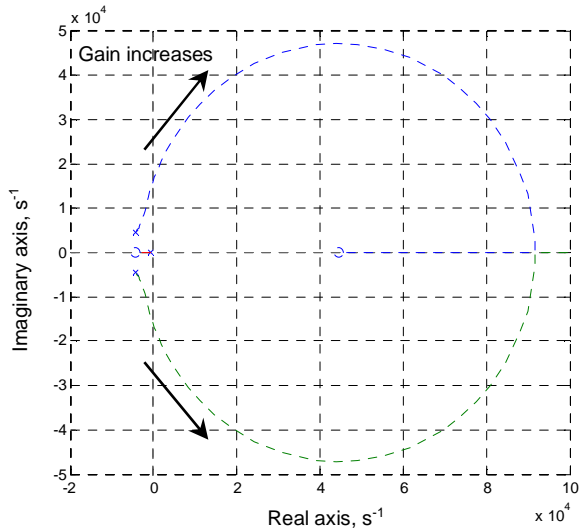

Figure 4. Open loop root locus of $E_{d c}$ plant operating at $32 \mathrm{krpm}$.
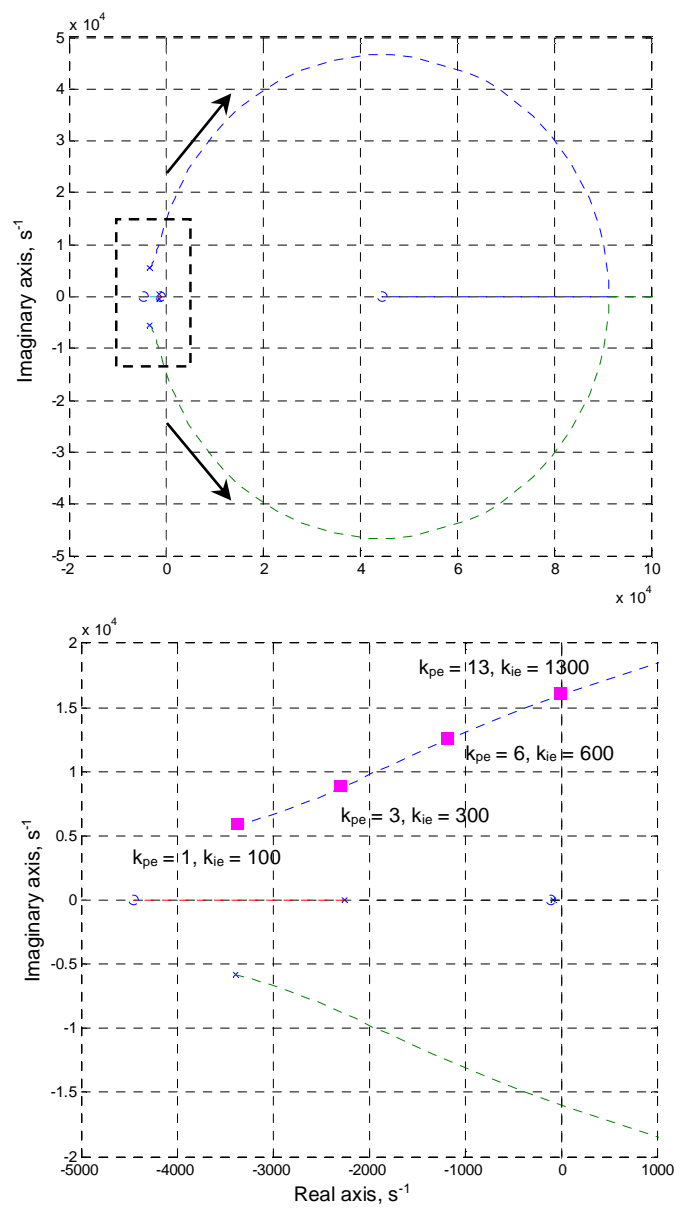

Figure 5. Closed loop root locus with PI (above) and zoomed area (below) showing pole positions at different controller gain values.

Page 3 of 6 


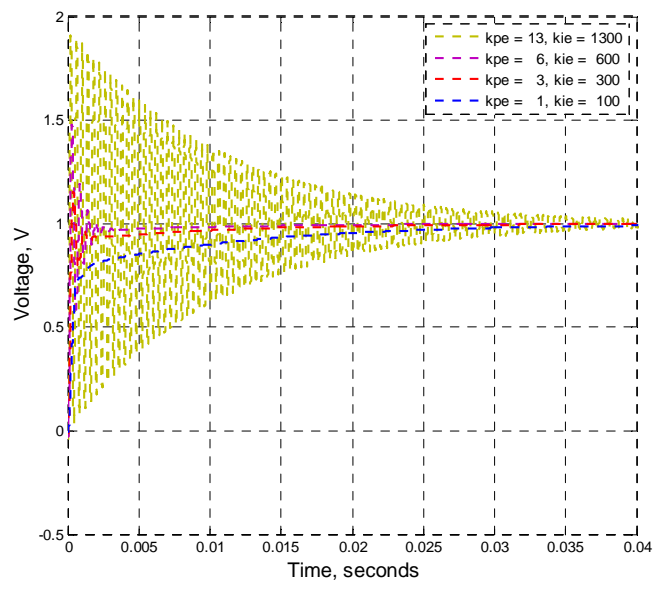

Figure 6. Closed loop $E_{d c}$ step responses to reference value $=1 \mathrm{~V}$ for various $k_{p e}$ and $k_{i e}$ combinations.

\section{Flux Weakening Controller Design}

The FW plant is derived specifically in generator mode for controller stability analysis that was designed in starter mode. The FW controller has been designed and its stability analyzed in starter mode [11]. Since the initial speed controller for starter mode is switched to $E_{d c}$ controller, the stability aspects may change and could affect the performance of the FW controller in generator mode. The plant is derived to relate output $\partial|V|$ to input $\partial i_{d}{ }^{*}$. It is derived using equations (6), (7), and (9):

$\partial|V|=\frac{1}{|V|_{0}}\left[\begin{array}{c}\left(\omega_{e 0} L_{d} v_{q 0}+R v_{d 0}+L_{d} s v_{d 0}\right) \partial i_{d} \\ +\left(R v_{q 0}+L_{q} s v_{q 0}-\omega_{e 0} L_{q} v_{d 0}\right) \partial i_{q} \\ +\left(L_{d} i_{d 0} v_{q 0}+\psi_{m} v_{q 0}-L_{q} i_{q 0} v_{d 0}\right) \partial \omega_{e}\end{array}\right]$

Similar to equation (11), $\partial|V|$ is found to be influenced by $\partial i_{d}{ }^{*}, \partial i_{q}{ }^{*}$, and $\partial \omega_{e}$. With the assumption of constant $\partial \omega_{e}$ and $\partial i_{q}{ }^{*}$ as disturbances, the plant is simplified together with (10):

$\partial|V|=\frac{1}{|V|_{0}} T F_{i d}(s)\left[\left(\omega_{e 0} L_{d} v_{q 0}+R v_{d 0}+L_{d} s v_{d 0}\right)\right] \partial i_{d}{ }^{*}$

The derived FW plant is verified with equivalent non-linear Simulink model in generator mode and good correlation between the step responses is achieved. The transfer function in the same operating point ( $32 \mathrm{krpm}$ under full load) is shown as:

$\frac{\partial|V|}{\partial i_{d}{ }^{*}}=\frac{0.46812\left(s+1.598 \times 10^{4}\right)(s+4449)}{\left(s^{2}+8884 s+3.948 \times 10^{7}\right)}$

All of the poles and zeroes of the FW plant are on the LHP which shows minimum phase characteristics. Analysis reported in [11] and [12] showed non-minimum phase nature during operation in starter mode. This change would mean that the controller stability range for FW increases when operating in generator mode. Using a pure integral controller, the closed loop root locus is shown in Figure 7. As the controller gain increases, the conjugate poles moves towards the LHP.
The step response with different FW controller integral gain, $k_{i v}$, is shown in Figure 8. The response when $k_{i v}=1500$ is satisfactory during operation in generator mode and it is selected for the FW controller.

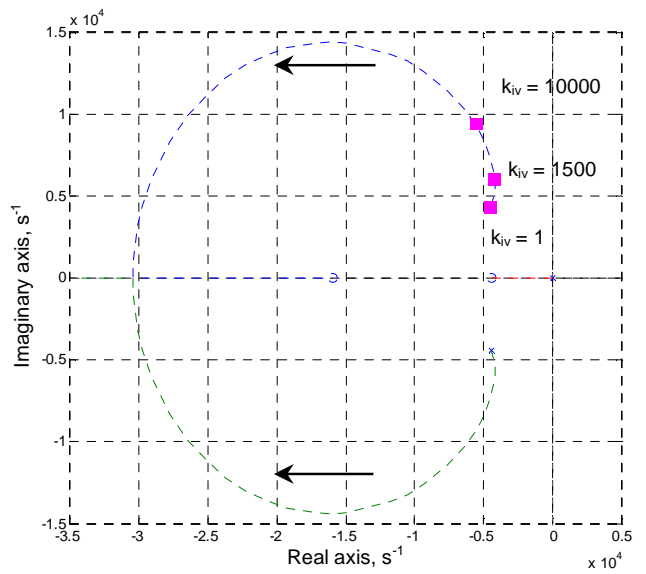

Figure 7. Closed loop root locus with pure integral controller showing pole positions at different gain values.

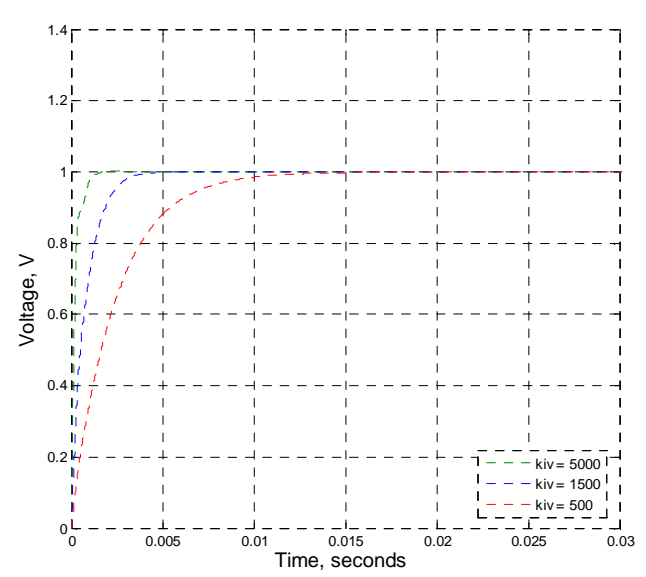

Figure 8. Closed loop $|V|$ step responses to reference value $=1 \mathrm{~V}$ for different $k_{i v}$

\section{Results and Discussion}

\section{Time domain simulation}

The designed controllers are tested in simulation with the nonlinear Simulink model. The relevant control parameters are shown in Table 2.

Table 2. Parameters of the control scheme.

\begin{tabular}{|l|c|}
\hline \multicolumn{1}{|c|}{ Parameter } & Value \\
\hline Inner current loop controller proportional term, $k_{p c}$ & 0.87 \\
\hline Inner current loop controller integral term, $k_{i c}$ & 3908 \\
\hline Outer $E_{d c}$ loop reference value, $E_{d c}{ }^{*}$ & $270 \mathrm{~V}$ \\
\hline Outer FW loop reference value, ||$^{*}$ & $156 \mathrm{~V}$ \\
\hline Maximum current load at $45 \mathrm{~kW}, i_{L}$ & $170 \mathrm{~A}$ \\
\hline
\end{tabular}

Page 4 of 6 
Figure 9 shows the responses when operating in generator mode with the designed controllers. The generator system is subjected to loads at intervals of $0.1 \mathrm{~s}$ that accumulates to the full load current capacity (170A based on $45 \mathrm{~kW}$ at $270 \mathrm{VDC}$ bus voltage). At each load impact, $E_{d c}$ and $|V|$ are regulated back to their reference values. $i_{d, q}$ is adjusted accordingly to supply sufficient power for the loads and to maintain $|V|$ within the limits. $i_{q}$ is seen as negative to denote power flow moving to the DC bus in the generator system. This shows that the designed controllers are able to work properly even at the highest operating speed and load for this generator system.

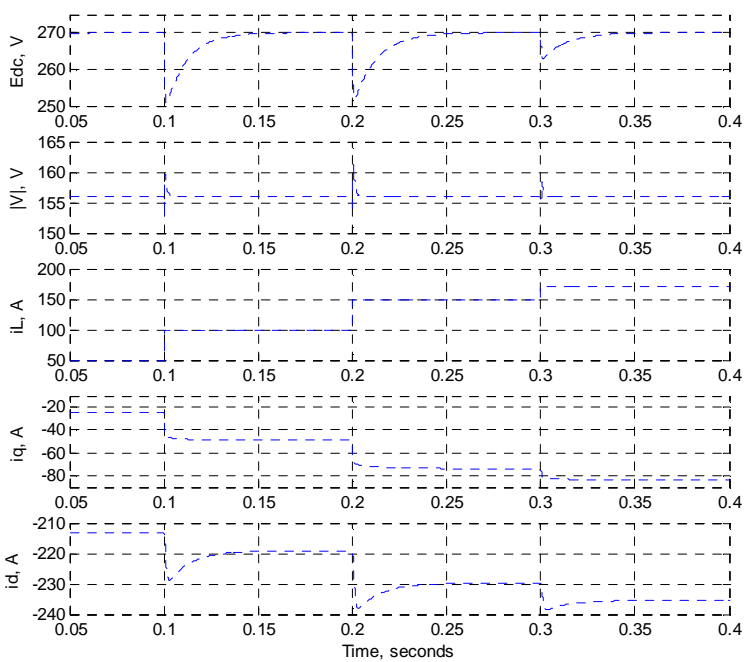

Figure 9. Responses of key variables to electrical loads, $i_{L},=100 \mathrm{~A}, 150 \mathrm{~A}$, and $170 \mathrm{~A}$ at $t=0.1 \mathrm{~s}, 0.2 \mathrm{~s}$, and $0.3 \mathrm{~s}$ respectively

\section{Experimental Results}

A small scale experimental rig is built that consists of a $2.5 \mathrm{~kW}$ PMM and a $4.8 \mathrm{~kW}$ DC machine with their respective drives seen in Figure 10. The DC machine fulfills the role of the aircraft engine to provide load torque for both starter and generator modes. The PMM is driven by a two-level PWM converter at $12.5 \mathrm{kHz}$ and is controlled by a DSP/FPGA control platform. The control performance of this test bench in generator mode is analyzed to validate the control design process in this paper.

The key parameters of this test bench and controllers are recorded in the Appendix. The controllers are redesigned to be compatible with the test bench parameters. The inner current loop controllers are designed to achieve $300 \mathrm{~Hz}$ bandwidth while the outer loop controller gains are selected based on the worst case operating point (4krpm with 5A DC load).

Figure 11 shows the steady state responses of the key control variables during generator mode operation at $3.6 \mathrm{krpm}$. At approximately $t=0.37 \mathrm{~s}$, the initial resistive load of $320 \Omega$ is disconnected from the DC bus. $E_{d c}$ and $|V|$ are regulated back to their reference values even after the load disconnection. The controllers respond satisfactorily in the event of load changes.

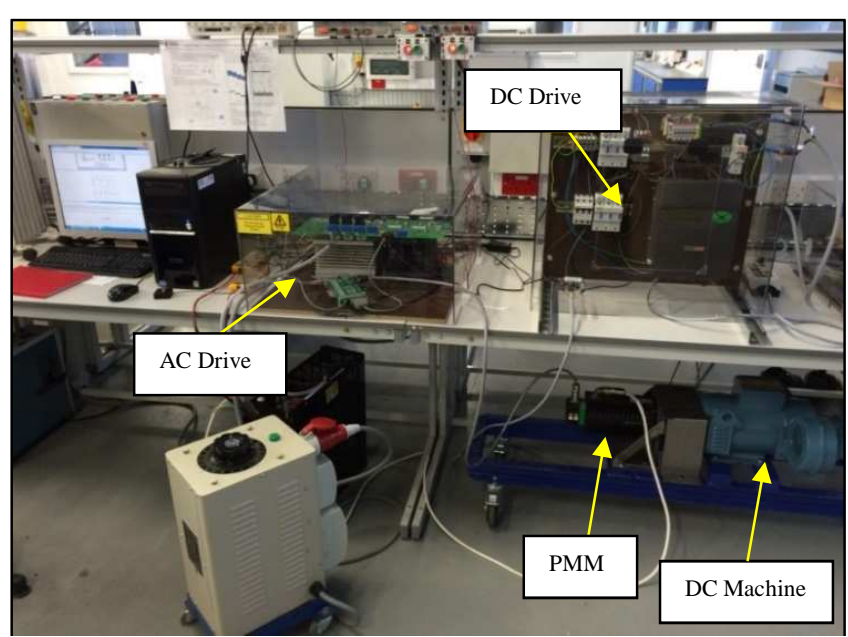

Figure 10. Experimental test bench.

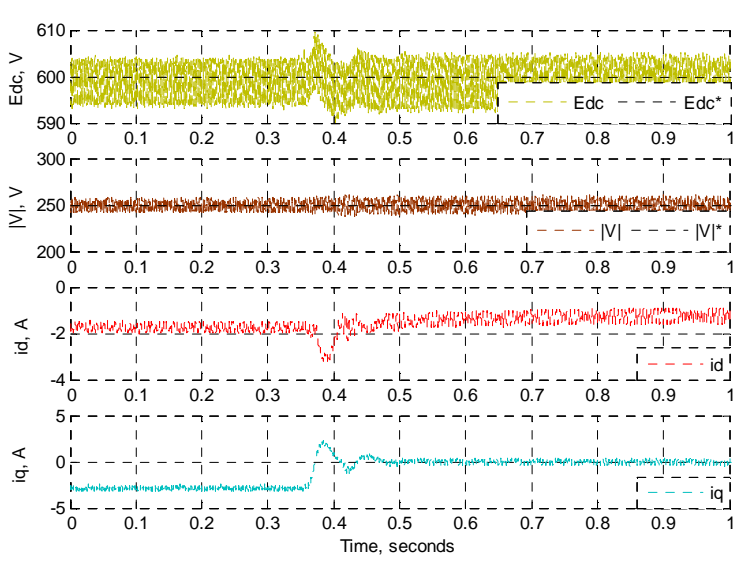

Figure 11. Controlled variable responses when operating at $3.6 \mathrm{krpm}$ with unloading at $t=0.37 \mathrm{~s}$.

\section{Conclusion}

The control design of a MEA generator system based on a PMM fed by AFE was investigated in this paper. FW and $E_{d c}$ control were considered to meet the performance requirements in generator mode. The control scheme was formed based on the control requirements. Their respective control plants were derived with appropriate assumptions for small signal analysis. These plants were verified with equivalent non-linear models built in Matlab/Simulink around a fixed operating point. The $E_{d c}$ plant exhibited non-minimum phase characteristics; a positive zero located on the root locus LHP. Its corresponding controller has to be carefully designed as there is a limited stability gain range. The FW plant was found to be minimum phase in generator mode compared to non-minimum phase during motoring mode reported in previous publications. This would mean that the controller has more stability range when operating in generator mode. The controllers were designed based on the worst case operating point to allow stable control throughout the speed and load operating range. The performance of the designed controllers was tested in time domain simulation with the non-linear Simulink model. An experimental test bench was also constructed to verify the control design process. Both sets of results showed successful control performance even when operating close to the worst case operating point. 


\section{References}

[1] A. AbdElhafez., A. J. Forsyth. A Review of More-Electric Aircraft AEROSPACE SCIENCES \& AVIATION TECHNOLOGY,ASAT- 13, May 26 - 28, 2009

[2] MITCHAM A.J., CULLEN J.J.A.: 'Permanent magnet generator options for the more electric aircraft'. Int. Conf. on Power Electronics, Machines and Drives, (Conf. Publ. No. 487), June 2002, pp. 241-245

[3] Patrick W Wheeler, Jon C Clare, Andrew Trentin, Serhiy Bozhko, "An overview of the more electrical aircraft", Proceedings of the Institution of Mechanical Engineers Part G Journal of Aerospace Engineering, 2012, 227(4):578-585

[4] Serhiy Bozhko, Seang Shen Yeoh, Fei Gao, Christopher Hill, "Aircraft Starter-Generator System based on Permanent-Magnet Machine fed by Active Front-End Rectifier" Department of Electrical and Electronic Engineering, University of Nottingham, United Kingdom

[5] F. Gao, S. Bozhko, Y. S. Shen, and G. Asher, "Control design for PMM starter-generator operated in flux-weakening mode", 48th Power Engineering Conference (UPEC), Dublin, September 2013.

[6] A. Abdel-Hafez, Power Generation and Distribution System for a More Electric Aircraft - A Review,Recent Advances in Aircraft Technology, 2012.

[7] K. Emadi and M. Ehsani, "Aircraft power systems: technology, state of the art, and future trends,"Aerospace and Electronic Systems Magazine, IEEE, vol. 15, pp. 28-32, 2000.

\section{Appendix}

Test bench and control parameters:

\begin{tabular}{|l|c|}
\hline \multicolumn{1}{|c|}{ Parameter } & Value \\
\hline Stator resistance, $R$ & $1.2 \Omega$ \\
\hline$d$-axis inductance, $L_{d}$ & $6.17 \mathrm{mH}$ \\
\hline$q$-axis inductance, $L_{q}$ & $8.379 \mathrm{mH}$ \\
\hline Mutual flux, $\psi_{m}$ & $0.23 \mathrm{Vs}$ \\
\hline Combined inertia, $J$ & $0.0116 \mathrm{kgm}^{2}$ \\
\hline Mechanical friction, $f_{c}$ & $0.5372 \mathrm{Nm}$ \\
\hline DC link capacitor, $C$ & $4.7 \mathrm{mF}$ \\
\hline Maximum stator current, $i_{m}$ & $8 \mathrm{~A}$ \\
\hline
\end{tabular}

[8] W. Shanshan and L. Yongdong, "Application and challenges of power electronics for variable frequency electric power system of more electric aircraft," in Electrical Machines and Systems (ICEMS), 2011 International Conference on, 2011, pp. 1-4.

[9] F. Khatounian ; E. Monmasson ; F. Berthereau ; E. Delaleau; J.P.Louis, "Control of a Doubly Fed Induction Generator for Aircraft Application", Industrial Electronics Society, 2003. IECON '03. The 29th Annual Conference of the IEEE

[10] Antonio Griffo; David Drury; Tadashi Sawata; Senior Member; IEEE and Phil H.Mellor, "Sensorless starting of a wound-field synchronous starter/generator for aircraft applications", IEEE TRANSACTIONS $\mathrm{OF}$ INDUSTRIAIL ELECTRONICS,VOL.59,NO.9,SEPTEMBER 2012

[11] S. S. Yeoh, F. Gao, S. Bozhko, G. Asher, "Control design for PMM-based starter generator system for More Electric Aircraft", Power Electronics and Applications (EPE'14-ECCE Europe), 2014 16th European Conference on, Publication Year: 2014 , Page(s): $1-10$

[12] S. Bozhko, S. S. Yeoh, F. Gao, T. Yang, C.Hill, "Control Design for Electric Starter-Generator Based on a High-Speed PermanentMagnet Machine Fed by an Active Front-End Rectifier", SAE Technical Paper 2014-01-2139.

\begin{tabular}{|l|c|}
\hline \multicolumn{1}{|c|}{ Parameter } & Value \\
\hline$i_{d}$ loop controller proportional term, $k_{p d}$ & 13.8 \\
\hline$i_{d}$ loop controller integral term, $k_{i d}$ & 9470 \\
\hline$i_{q}$ loop controller proportional term, $k_{p q}$ & 18.7 \\
\hline$i_{q}$ loop controller integral term, $k_{i q}$ & 12543 \\
\hline$E_{d c}$ loop controller proportional term, $k_{p e}$ & 0.1 \\
\hline$E_{d c}$ loop controller integral term, $k_{i e}$ & 100 \\
\hline FW loop controller integral term, $k_{i v}$ & 100 \\
\hline$E_{d c}$ reference value, $E_{d c}{ }^{*}$ & $600 \mathrm{~V}$ \\
\hline FW reference value, $|V|^{*}$ & $250 \mathrm{~V}$ \\
\hline
\end{tabular}

Page 6 of 6 